\title{
MedChemComm
}

Check for updates

Cite this: Med. Chem. Commun., 2018, 9, 982

Received 28th February 2018, Accepted 24th April 2018

DOI: 10.1039/c8md00113h

rsc.li/medchemcomm

\section{Synthesis and cellular penetration properties of new phosphonium based cationic amphiphilic peptides $\dagger$}

\author{
Ezequiel Silva Nigenda, ${ }^{a}$ Tobias M. Postma, ${ }^{a}$ Mohammed Hezwani, ${ }^{a}$ Alin Pirvan, ${ }^{a}$ \\ Susan Gannon, ${ }^{a}$ Carol-Anne Smith, ${ }^{b}$ Mathis Riehle iD ${ }^{b}$ and Rob M. J. Liskamp (iD *a
}

\begin{abstract}
A new category of phosphonium based cationic amphiphilic peptides has been developed and evaluated as potential antimicrobial peptides and cell penetrating peptides. The required building blocks were conveniently accessible from cysteine and could be applied in a solid phase peptide synthesis protocol for incorporation into peptide sequences. Evaluation of the antimicrobial properties and cellular toxicity of these phosphonium based peptides showed that these "soft" cationic side-chain containing peptides have poor antimicrobial properties and most of them were virtually non toxic (on HEK cells tested at 256 and $512 \mu \mathrm{M}$ ) and non-haemolytic (on horse erythrocytes tested at $512 \mu \mathrm{M}$ ), hinting at an interesting potential application as cell penetrating peptides. This possibility was evaluated using fluorescent peptide derivatives and showed that these phosphonium based peptide derivatives were capable of entering HEK cells and depending on

the sequence confined to specific cellular areas.
\end{abstract}

\section{Introduction}

Cationic amphiphilic peptides (CAPs) are a class of compounds that are attracting extensive attention in medicinal chemistry because of their wide range of biological activities. The broad spectrum antimicrobial properties of antimicrobial peptides (AMPs) ${ }^{1}$ are of great interest for the development of potential new antibiotics, since as compared to the widely used small molecule antibiotics, virtually no resistance has been observed so far. ${ }^{2}$ Also, the membrane permeation capabilities of cell penetrating peptides (CPPs) ${ }^{3}$ and their low toxicity or side effects, will become increasingly important for the intra-cellular delivery of small molecule drugs and biologics. ${ }^{4-6}$

All these activities are a consequence of the amphipathic nature of CAPs conferred by the presence of both hydrophobic amino acid residues (Trp, Phe, Leu) and basic amino acid residues (Lys, Arg, His) leading to a net positive charge of CAPs. ${ }^{7}$ The role of positively charged amino acids in CAPs is especially noteworthy, since they form the anchors for interactions with the negatively charged phospholipids. Bacterial membranes are net negatively charged because of the pres-

\footnotetext{
${ }^{a}$ School of Chemistry, University of Glasgow, Joseph Black Building, University Avenue, Glasgow G12 8QQ, UK. E-mail: robert.liskamp@glasgow.ac.uk ${ }^{b}$ Centre for Cell Engineering, Institute of Molecular, Cell and Systems Biology, Joseph Black Building, University Avenue, Glasgow G12 8QQ, UK

$\dagger$ Electronic supplementary information (ESI) available. See DOI: 10.1039/ c8md00113h
}

ence of anionic phospholipids such as phosphatidylglycerol and phosphatidylserine in Gram-negative bacteria, ${ }^{2}$ or teichoic and lipoteichoic acids in Gram-positive bacteria. ${ }^{8}$ In contrast, eukaryotic cell membranes are composed of more neutral zwitterionic lipids like phosphatidyl choline and cholesterol. In these cells, the anionic lipids are located in the inner part of the plasma membrane.

The cytotoxic effect on both prokaryotic and eukaryotic cells is closely related to the structure of the CAPs and the nature of their interaction with the membranes. The presence in CAPs of amino acid residues like tryptophan tends to lead to stronger interactions with membranes causing lysis, whereas leucine tends to increase the lipophilicity of CAPs facilitating crossing membranes. ${ }^{9}$ Also, the replacement of very hydrophobic residues in the apolar face of CAPs, by less hydrophobic amino acid residues reduces interaction with red blood cell membranes leading to diminished haemolysis. ${ }^{10}$

This duality in the behaviour of the CAPs is fascinating and poses a great challenge for tuning their activity. In many cationic antimicrobial peptides, this can be achieved by altering the balance between the charged and hydrophobic residues. ${ }^{11}$ Therefore, in this research, we wished to look at the charge character of the positively charged amino acids by changing the naturally occurring positively charged nitrogen amino acids to positively charged phosphorus containing amino acids. To our knowledge, the influence on the bioactivity of CAPs containing other positively charged atoms has not been studied so far. By introducing phosphonium amino acids, we can study the triangular relation between 


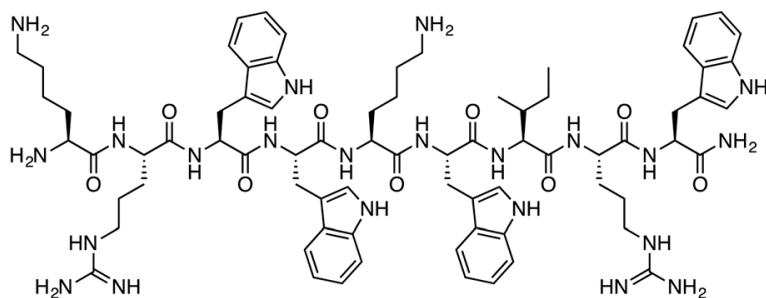

Fig. $1 \mathrm{HHC10}$ cationic amphiphilic peptide developed by Hancock et al. ${ }^{12}$

antimicrobial activity (AM), cell penetrating ability (CP) and cellular toxicity (CT) of a new class of CAPs. Determination of the relative AM, CP and CT parameters, should steer us ultimately towards cationic amphiphilic peptides with optimal activity and selectivity. It might be even possible that, by judicious modification of the sequences, we will be able to tune the AM, CP and CT properties.

As a suitable starting point for our studies we chose HHC10, a well-known antimicrobial peptide developed in the group of Hancock, ${ }^{12}$ (Fig. 1) which is an optimized AMP with low cytotoxicity properties as was evidenced from its low haemolysis properties. HHC10 has potent broad-spectrum antimicrobial activity against multidrug resistant superbugs in vitro but the presence of Lys and Arg residues, makes HHC10 also susceptible to proteolytic digestion by trypsinlike proteases. ${ }^{13}$ An attractive possibility to reduce this proteolytic degradation is the incorporation of D-amino acids. For example, we have recently shown that synthesis of the D-isomer of the HHC10 peptide led to an increase of its stability in serum and subsequent incorporation into a coating $^{\mathbf{1 4 , 1 5}}$ led to a serum-stable antimicrobial coating. Thus, introduction of other unnatural amino acids such as analogues of the positively charged lysine and arginine residues with a different positively charged atom, that is not recognised by proteolytic enzymes, may favourably affect the bioactivity or stability.

In this work we describe the development of these new positively charged amino acids, containing a phosphonium moiety, used in the synthesis of new CAPs with possible medicinal chemistry applications. The antimicrobial and cyto- toxic activities of these phosphonium-HHC10 analogues were studied, which led to the development of fluorescent versions to investigate their behaviour in mammalian cells and study of potential cell penetrating properties.

\section{Results and discussion}

Cysteine is perhaps the most versatile amino acid for postsynthesis modification by alkylation either in a peptide or a protein due to the excellent nucleophilic character of the thiol group. ${ }^{16}$ Work developed by Shokat et al., describes the functionalisation of cysteine to produce a series of methylated lysine analogues. ${ }^{17}$ By using suitable alkylating reagents containing a phosphonium group, it was possible to synthesise the phosphonium isosteric amino acid of (trimethylamine)lysine $6\left({ }^{\mathrm{P}} \mathrm{K}\right.$ ) ) and one as a more distant analogue of the positive charge present in the side chain of arginine 7 (' $R^{\mathrm{P}}$ ').

The required bromo phosphonium alkylating reagents 4 and 5 were prepared by addition of trimethyl phosphine to 1,2-dibromo ethane and 1,3-dibromo propane, respectively. Using 4, it was possible to prepare the pure phosphonium cysteine derivative 6 directly from Fmoc-Cys-OH 2. However, to facilitate purification of phosphonium derivative 7 , synthesis was more conveniently carried out starting from FmocCys-OMe 3, followed by ester hydrolysis under the acidic conditions of the work up (Scheme 1).

In principle, it is possible to introduce the desired phosphonium cysteine derivatives post-assembly of the peptides in which the positively charged chains must be incorporated. This can be achieved by alkylation of deprotected cysteine derivatives using alkylating agents 4 or $\mathbf{5}$. However, it was found that completion of the alkylation reactions was difficult to realize in peptides containing more than one cysteine residue. In addition, peptides (for example CAP 9) containing two different phosphonium cysteine derivatives cannot be synthesized post-assembly. Hence, it was decided to employ the modified amino acid building block approach and use Fmoc protected derivatives 6 and 7 in a manual solid phase synthesis approach on Rink amide resin. ${ }^{18}$ To synthesise the three different HHC10 phosphonium analogues 8-10 (Fig. 2), DIC/

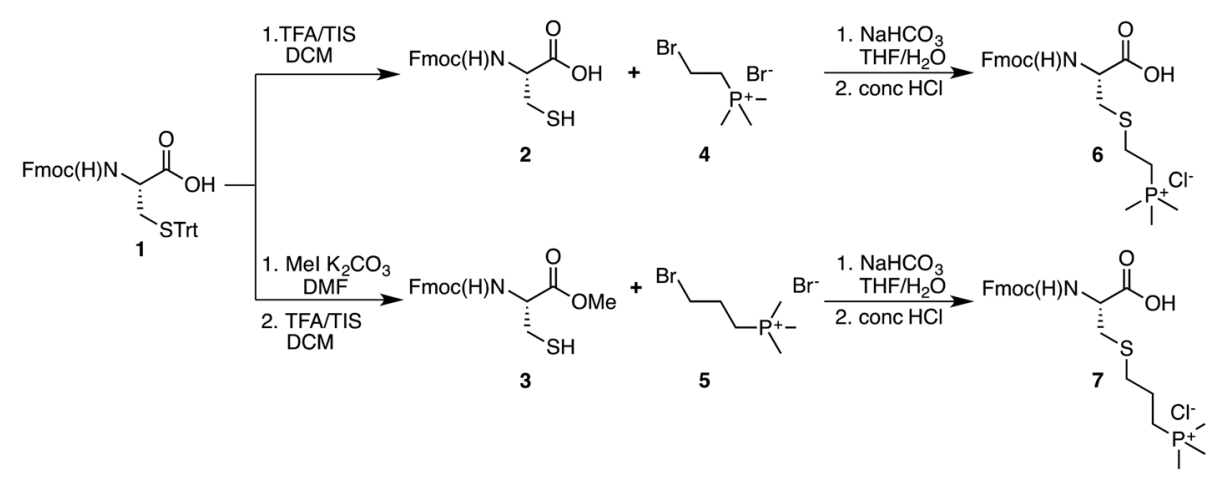

Scheme 1 Synthesis of the phosphonium containing amino acid derivatives. 

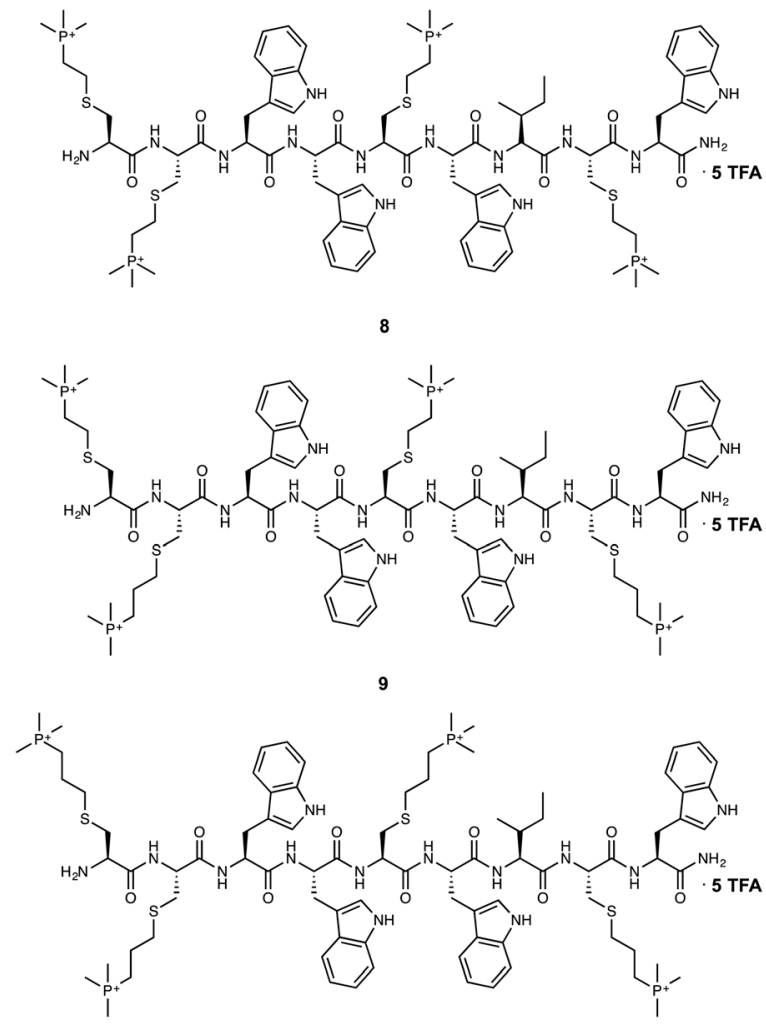

10

Fig. 2 HHC10 derivatives with the phosphonium charged amino acids.

Oxyma-pure was used as a coupling reagent after failed attempts of using HCTU/DIPEA. After cleavage and deprotection, crude peptides were purified by reverse phase HPLC and obtained with purities $>97 \%$.

For the evaluation of the bio-activity of phosphonium CAPs 8-10 their antimicrobial properties, (eukaryotic) cellular toxicity and haemolytic activity were determined (Table 1).

Determination of the antimicrobial activity using the modified MIC method for cationic amphiphilic peptides developed by Hancock and co-workers ${ }^{19}$ showed that peptides CAPs 8-10 were virtually inactive towards $E$. coli compared to HHC10. This inactivity towards bacteria was paralleled by a lower cellular toxicity towards HEK 293 cells as compared to

Table 1 Antimicrobial and cytotoxicity evaluation of the phosphonium based HHC10 analogues and comparison with HHC10: lower antimicrobial activities of the phosphonium peptides are translated into a diminished toxicity profile as compared to HHC10. All experiments were carried out in triplicate and cell viability and haemolytic effect are presented as the mean \pm SEM

\begin{tabular}{|c|c|c|c|}
\hline CAP & $\begin{array}{l}\text { MIC on } \\
E . \operatorname{coli}(\mu \mathrm{M})\end{array}$ & $\begin{array}{l}\text { Cell viability of } \\
\text { HEK } 293 \text { cells } \\
\text { at } 256 \mu \mathrm{M}(\%)\end{array}$ & $\begin{array}{l}\text { Haemolysis of } \\
\text { horse erythrocytes } \\
\text { at } 512 \mu \mathrm{M}(\%)\end{array}$ \\
\hline 8 & 64 & $85 \pm 6$ & $3.4 \pm 0.1$ \\
\hline 9 & 64 & $87 \pm 4$ & $3.3 \pm 0.1$ \\
\hline 10 & 128 & $103 \pm 3$ & $3.2 \pm 0.1$ \\
\hline HНC10 & 1.5 (ref. 21) & $2.0 \pm 1.5$ & $14.3 \pm 3.6$ \\
\hline
\end{tabular}

HHC10 using the Alamar blue assay. ${ }^{20}$ The haemolytic activity of CAPs 8-10 was also considerably lower than that of HHC10, which is known to possess relatively low haemolytic properties.

The considerable antimicrobial activity of HHC10 is probably related to the high interaction properties of Arg/ Trp rich peptides with bacterial membranes. ${ }^{22}$ Similarly, HHC10 can interact with membranes of mammalian cells, which led to a decrease of cell viability and increase of the haemolytic activity. However, the increased size of the phosphorus atom as well as the presence of methyl groups likely led to a more diffuse positive charge of the side chains of the phosphonium CAPs and therefore less strong interaction with the negatively charged bacterial membrane, thereby decreasing the antimicrobial effect. Concomitantly, this decrease of the positive charge character might be responsible for the diminished eukaryotic toxicity and haemolysis of CAPs 8-10.

This relatively low toxicity of CAPs 8-10 prompted us to investigate two additional phosphonium containing peptides that might have better antimicrobial properties. To achieve this, Trp amino acid residues were changed to Phe-residues in the repetitive sequence $\mathrm{X}^{\mathrm{P}} \mathrm{FFX}^{\mathrm{P}} \mathrm{FFX}^{\mathrm{P}} \mathrm{FFX}^{\mathrm{P}}\left({ }^{\prime} \mathrm{X}^{\mathrm{P}}\right.$, represents an incorporated phosphonium amino acid) leading to 11 and 12, which were synthesized by solid phase peptide synthesis (Fig. 3). This sequence is based on the cationic bactericidal peptide KFFKFFKFFK previously used by our group ${ }^{23}$ which was reported to have a direct activity against $E$. $c o l i^{24}$ and low eukaryotic toxicity and haemolysis.

Interestingly, the antimicrobial activity of 11 and 12 increased slightly (MIC 32 and $64 \mu \mathrm{M}$, respectively), but was still considerably less than that of HHC10 (1.5 $\mu \mathrm{M})$. According to Eriksson et al., ${ }^{25}$ the KFFKFFKFFK sequence acts as a cell-permeabilising peptide for the delivery of peptide nucleic acids, thus hinting at possible favourable cell penetrating properties of $\mathbf{1 1}$ and $\mathbf{1 2 .}$

To investigate the potential cell penetrating properties induced by the phosphonium containing amino acid residues,

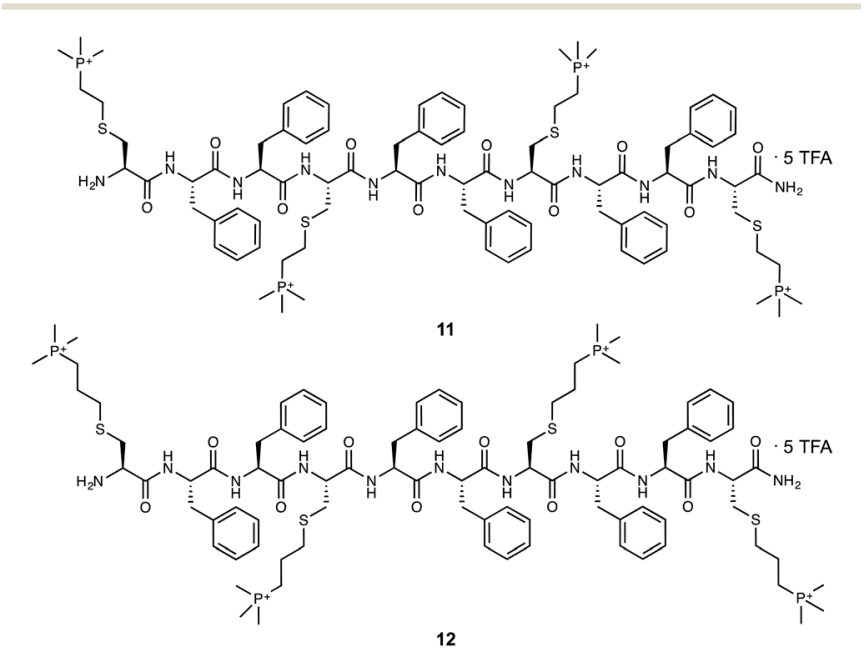

Fig. 3 Phosphonium analogues of the bactericidal peptide KFFKFFKFFK. 
a small collection of peptides in which the Phe-residues in the $\mathrm{X}^{\mathrm{P}} \mathrm{FFX}^{\mathrm{P}} \mathrm{FFX}^{\mathrm{P}}$ FFX $^{\mathrm{P}}$ sequence of peptides 11 and 12 were changed by other common hydrophobic residues (Trp, Leu, Ile), was synthesised thereby affording six additional phosphonium-CAPs (13-18) (Fig. 5). The cytotoxicity of these compounds was tested and compared to compounds 11 and 12 trying to understand the relation of the hydrophobic residues on the activity of the phosphonium-CAPs (Table 2).

Replacement of the phenylalanine residues by tryptophan residues in the peptide increased the cytotoxicity of the phosphonium-CAPs as was evidenced by compound 13 which led to a very low cell viability and the highest haemolytic effect of all synthesised peptides. In addition, interaction of Trp rich sequences with membrane components and disruption of red blood cells was increased as comparison of the haemolytic effect of compounds with similar cell viability like compounds 11 and 14 showed. The latter had a higher haemolytic activity. Peptides 15-18 showed a lower toxicity on red blood cells.

Nevertheless, the generally low toxicity of these phosphonium CAPs is remarkable. We think that this is due to the character of these added positively charged amino acids as compared to the positively charged amino acid residues (Arg, Lys, His), which are normally found in antimicrobial peptides and cytotoxic peptides. The phosphonium charge is much more diffuse and therefore interaction with the negative charges of the lipids are weaker, possibly sufficient for cell penetrating properties but less strong for a display of toxicity effects or antimicrobial activity.

To evaluate possible cell penetrating properties of phosphonium CAPs, fluorescent derivatives of the phosphonium HHC10 analogues (8-10) and $\mathrm{X}^{\mathrm{P}} \mathrm{FFX}^{\mathrm{P}} \mathrm{FFX}^{\mathrm{P}} \mathrm{FFX}^{\mathrm{P}}$ peptide sequences $(\mathbf{1 1}, \mathbf{1 2})$ were prepared. These peptides were selected because of their similarly low antimicrobial and low cytotoxic activities, thereby rendering them potentially interesting to serve as cell penetrating peptide carriers for future cargos.

For visualization by fluorescence microscopy the BODIPYFl label, which was prepared according to a modified literature procedure, ${ }^{26}$ was coupled to the $\mathrm{N}$ terminus of the peptide mimics using EDCI.HCl and 6-Cl HOBt in DMF leading to fluorescent BODIPY-CAPs 19-23 (Fig. 4).

MCF7 cells were incubated with solutions $(20 \mu \mathrm{M})$ of the fluorescent peptides according to a slightly modified literature protocol (Fig. 5). ${ }^{27}$ These cells were used because of their well-known morphology and controlled grow rate. The cells were observed with an Axiovert fluorescent microscope. Controls using the fluorescent BODIPY ligand were carried out to confirm that the green fluorescence was due to the presences of the fluorescent peptides (see ESI $\dagger$ ).

The observed association of the fluorescent CAPs with membranes was not merely due to the CAPs associating with just any lipid containing organelle, since neither Golgi, ER nor mitochondria were stained. The staining was diffuse

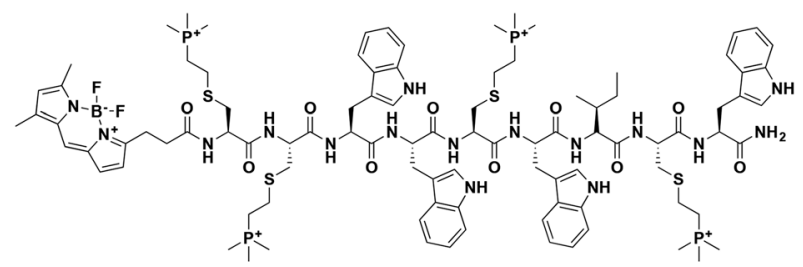

19: Bodipy-KPKPWWKPWIKPW-NH

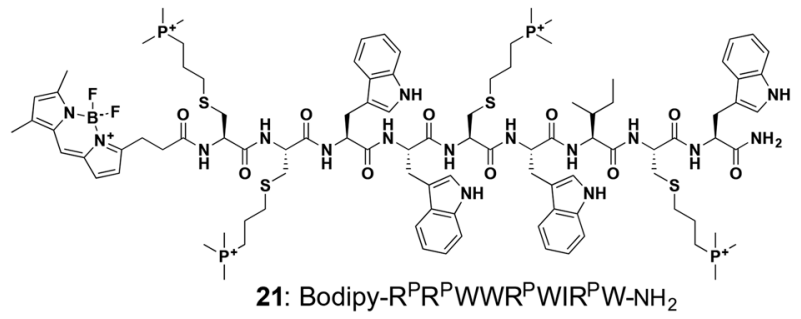

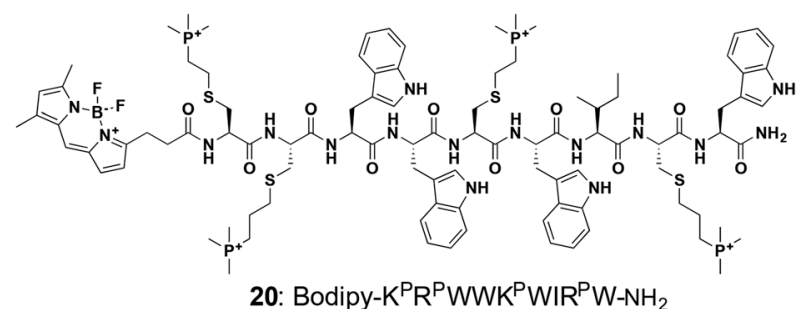

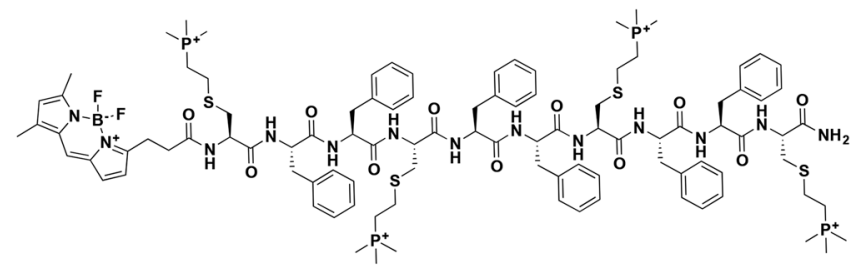

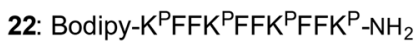

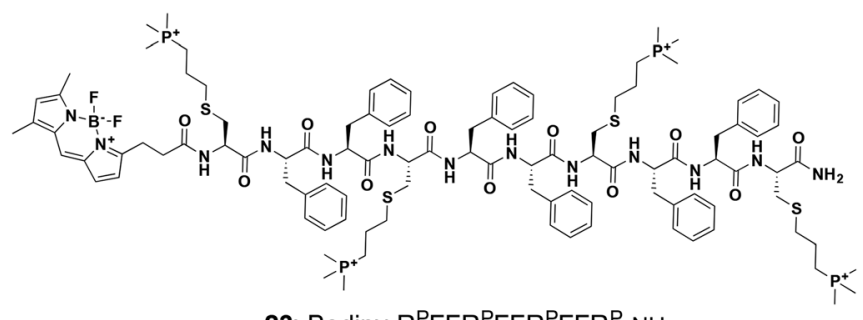

23: Bodipy-RPFFRFFRPFFR ${ }^{\mathrm{P}}-\mathrm{NH}_{2}$

Fig. 4 Green fluorescent phosphonium peptides. 


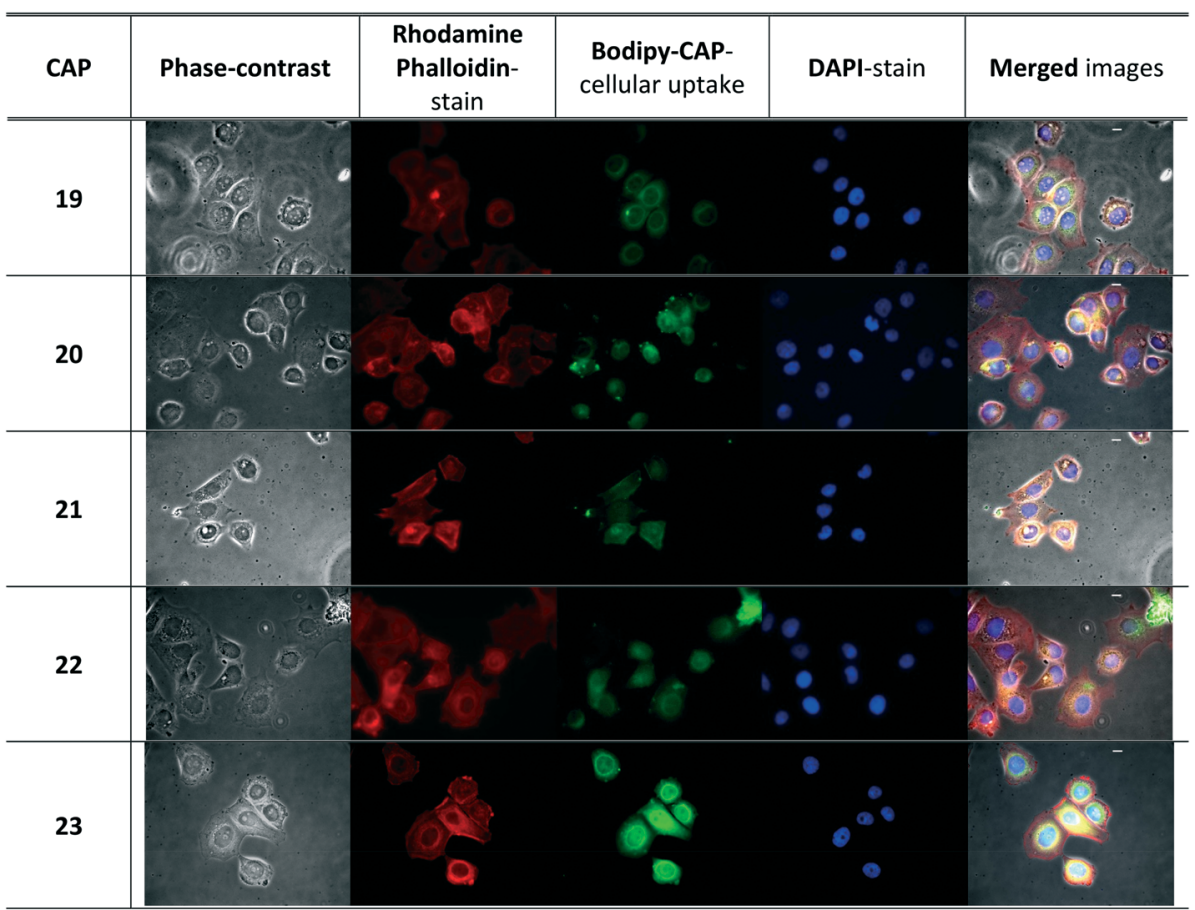

Fig. 5 Fluorescence micrographs of MCF7 cells with $20 \mu \mathrm{M}$ of BODIPY-CAPs 19, 20, 21, 22 and 23. Blue fluorescence of DAPI (4',6diamidinophenylindole) stained nuclei and red fluorescent components of the cytoskeleton were obtained by marking with Rhodamine phalloidin. Green (BODIPY) fluorescent cationic amphiphilic peptides showed their cellular uptake and localisation. Pictures were merged to visualise the localisation of the fluorescent peptides inside the cell thus confirming their cell penetrating properties. The white scale bar in the right figure of each frame is $10 \mu \mathrm{m}$.

throughout the cells but stayed in place. There was no real entry into the nucleus. In general, and perhaps not entirely unexpectedly, association of all fluorescent phosphonium CAPs seemed to be similar. Subtle differences in the staining may indicate the importance of structural variations of phosphonium CAPs. For example, tryptophan $/ \mathrm{K}^{\mathrm{P}}$ containing CAP 19 seemed to be uniformly distributed over membrane containing structures, whereas tryptophan $/ \mathrm{R}^{\mathrm{P}} / \mathrm{K}^{\mathrm{P}}$ containing CAP 20 showed staining of well localised areas in cell periphery with diffuse staining in the cytoplasm but not the nucleus. The bright actin patches were reflected in bright patches of the CAP. Tryptophan $/ \mathrm{R}^{\mathrm{P}}$ containing CAP 21 showed a more diffuse staining throughout the cytoplasm as no dark nuclear area was visible looking at the green fluorescence of CAP 21. Here also the bright actin patches were reflected in bright patches of the CAP. Phenylalanine $/ \mathrm{K}^{\mathrm{P}}$ containing CAP 22 showed a granular pattern and perinuclear staining with possible association with areas inside or around (Golgi-area) the nucleus. Finally, phenylalanine $/ \mathbf{R}^{\mathrm{P}}$ containing CAP 23 showed a less granular pattern than 22 with diffuse association with areas inside the nucleus. There was a very clear perinuclear staining and here too the actin bright patches were also bright in the bright patches of this CAP.

Table 2 Cytotoxicity evaluation of the phosphonium-CAPs: ' $\mathrm{K}^{\mathrm{P}}$, represents the phosphonium isostere of (trimethyl)lysine and ' $\mathrm{R}$ ' with a phosphonium side chain length comparable to that of arginine. All peptides are TFA salts with $\mathrm{C}$-terminal amide and free $\mathrm{N}$-terminus. All experiments were carried out in triplicate and cell viability and haemolytic effect are presented as the mean \pm SEM

\begin{tabular}{|c|c|c|c|}
\hline CAP & Sequence & $\begin{array}{l}\text { Cell viability of HEK } 293 \\
\text { cells at } 512 \mu \mathrm{M}(\%)\end{array}$ & $\begin{array}{l}\text { Haemolysis of horse } \\
\text { erythrocytes at } 512 \mu \mathrm{M}(\%)\end{array}$ \\
\hline 11 & 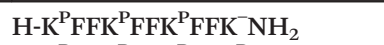 & $46 \pm 1$ & $1.5 \pm 0.1$ \\
\hline 12 & $\mathrm{H}-\mathrm{R}^{\mathrm{P}} \mathrm{FFR}^{\mathrm{P}} \mathrm{FFR}^{\mathrm{P}} \mathrm{FFR}^{\mathrm{P}-} \mathrm{NH}_{2}$ & $83 \pm 1$ & $3.1 \pm 0.1$ \\
\hline 13 & $\mathrm{H}-\mathrm{K}^{\mathrm{P}} \mathrm{WWK} \mathrm{K}^{\mathrm{P}} \mathrm{WWK} \mathrm{K}^{\mathrm{P}} \mathrm{WWK} \mathrm{K}^{\mathrm{P}-} \mathrm{NH}_{2}$ & $14 \pm 5$ & $11.0 \pm 1.6$ \\
\hline 14 & $\mathrm{H}-\mathrm{R}^{\mathrm{P}} \mathrm{WWR}{ }^{\mathrm{P}} \mathrm{WWR}{ }^{\mathrm{P}} \mathrm{WWR}{ }^{\mathrm{P}-} \mathrm{NH}_{2}$ & $44 \pm 1$ & $5.8 \pm 1.0$ \\
\hline 15 & $\mathrm{H}-\mathrm{K}^{\mathrm{P}} \operatorname{LLK}^{\mathrm{P}}$ LLK $^{\mathrm{P}}$ LLK $^{\mathrm{P}-} \mathrm{NH}_{2}$ & $110 \pm 21$ & $2.1 \pm 0.5$ \\
\hline 16 & $\mathrm{H}-\mathrm{R}^{\mathrm{P}} \operatorname{LLR}^{\mathrm{P}} \operatorname{LLR}^{\mathrm{P}} \operatorname{LLR}^{\mathrm{P}-} \mathrm{NH}_{2}$ & $93 \pm 3$ & $0.6 \pm 0.2$ \\
\hline 17 & $\mathrm{H}-\mathrm{K}^{\mathrm{P}} \mathrm{IIK}^{\mathrm{P}} \mathrm{IIK}^{\mathrm{P}} \mathrm{IIK}^{\mathrm{P}-} \mathrm{NH}_{2}$ & $120 \pm 23$ & $2.3 \pm 1.5$ \\
\hline 18 & $\mathrm{H}-\mathrm{R}^{\mathrm{P}} \operatorname{IIR}^{\mathrm{P}} \operatorname{IIR}^{\mathrm{P}} \operatorname{IIR}^{\mathrm{P}-} \mathrm{NH}_{2}$ & $83 \pm 29$ & $3.9 \pm 0.7$ \\
\hline HHC10 & H-KRWWKWIRW ${ }^{-} \mathrm{NH}_{2}$ & 0.0 & $14.3 \pm 3.6$ \\
\hline
\end{tabular}




\section{Conclusions}

A new class of positively charged non-natural amino acids derived from cysteine was synthesised. These were used to prepare a new category of cationic amphiphilic peptides that are less toxic than normal lysine or arginine based CAPs, possibly due to presence of a more diffused charge of the positive phosphonium moiety. Their antimicrobial activity is lower than the well-known AMP HHC10. However, their low toxicity and ability to cross membranes without causing damage was further investigated to evaluate possible cell penetrating properties. This study showed that introduction of phosphonium amino acids diminished the toxicity compared to of positively charged nitrogen containing peptides such as HHC10. Further modification of the sequence of the peptides by introduction of other lipophilic amino acid residues favoured their cell penetrating properties. The data showed that this class of phosphonium based CAPs may well comprise a new category of cell penetrating peptides with low cytotoxicity.

\section{Conflicts of interest}

The authors declare no competing interest.

\section{Acknowledgements}

E. S. $\mathbf{N}$ thanks the National Council of Science and Technology of Mexico (CONACyT) for financial support. Assistance by Dr Alex Hoose with MS-interpretation is gratefully acknowledged.

\section{References}

1 R. E. Hancock, Lancet Infect. Dis., 2001, 1, 156-164.

2 D. I. Andersson, D. Hughes and J. Z. Kubicek-Sutherland, Drug Resist. Updates, 2016, 26, 43-57.

3 D. M. Copolovici, K. Langel, E. Eriste and Ü. Langel, ACS Nano, 2014, 8, 1972-1994.

4 B. G. De La Torre, V. Hornillos, J. R. Luque-Ortega, M. A. Abengózar, F. Amat-Guerri, A. Ulises Acuña, L. Rivas and D. Andreu, Amino Acids, 2014, 46, 1047-1058.

5 T. Schröder, N. Niemeier, S. Afonin, A. S. Ulrich, H. F. Krug and S. Bräse, J. Med. Chem., 2008, 51, 376-379.

6 R. Mishra, W. Su, R. Pohmann, J. Pfeuffer, M. G. Sauer, K. Ugurbil and J. Engelmann, Bioconjugate Chem., 2009, 20, 1860-1868.

7 R. E. W. Hancock and H.-G. Sahl, Nat. Biotechnol., 2006, 24, 1551-1557.
8 N. Malanovic and K. Lohner, Biochim. Biophys. Acta, Biomembr., 2016, 1858, 936-946.

9 N. Wiradharma, U. Khoe, C. A. E. Hauser, S. V. Seow, S. Zhang and Y. Y. Yang, Biomaterials, 2011, 32, 2204-2212.

10 C. D. Fjell, J. A. Hiss, R. E. W. Hancock and G. Schneider, Nat. Rev. Drug Discovery, 2012, 11, 37-51.

11 I. Zelezetsky, U. Pag, H. G. Sahl and A. Tossi, Peptides, 2005, 26, 2368-2376.

12 A. Cherkasov, K. Hilpert, H. Jenssen, C. D. Fjell, M. Waldbrook, S. C. Mullaly, R. Volkmer-Engert and R. E. W. Hancock, ACS Chem. Biol., 2009, 4, 65-74.

13 M. Bagheri, S. Arasteh, E. F. Haney and R. E. W. Hancock, J. Med. Chem., 2016, 59, 3079-3086.

14 T. M. Postma and R. M. J. Liskamp, RSC Adv., 2016, 6, 94840-94844.

15 R. T. C. Cleophas, M. Riool, H. L. C. Quarles van Ufford, S. A. J. Zaat, J. A. W. Kruijtzer and R. M. J. Liskamp, ACS Macro Lett., 2014, 3, 477-480.

16 J. M. Chalker, G. J. L. Bernardes, Y. A. Lin and B. G. Davis, Chem. - Asian J., 2009, 4, 630-640.

17 M. D. Simon, F. Chu, L. R. Racki, C. C. de la Cruz, A. L. Burlingame, B. Panning, G. J. Narlikar and K. M. Shokat, Cell, 2007, 128, 1003-1012.

18 M. Mura, J. Wang, Y. Zhou, M. Pinna, A. V. Zvelindovsky, S. R. Dennison and D. A. Phoenix, Eur. Biophys. J., 2016, 45, 195-207.

19 I. Wiegand, K. Hilpert and R. E. W. Hancock, Nat. Protoc., 2008, 3, 163-175.

20 R. Hamid, Y. Rotshteyn, L. Rabadi, R. Parikh and P. Bullock, Toxicol. In Vitro, 2004, 18, 703-710.

21 R. E. W. Hancock, K. Hilpert, A. Cherkasov and C. Fjell, US8343475B2, 2013, vol. 1, pp. 205-223.

22 M. Nichols, M. Kuljanin, M. Nategholeslam, T. Hoang, S. Vafaei, B. Tomberli, C. G. Gray, L. DeBruin and M. Jelokhani-Niaraki, J. Phys. Chem. B, 2013, 117, 14697-14708.

23 T. M. Postma and R. M. J. Liskamp, RSC Adv., 2016, 6, 65418-65421.

24 M. Vaara and M. Porro, Antimicrob. Agents Chemother., 1996, 40, 1801-1805.

25 M. Eriksson, P. E. Nielsen and L. Good, J. Biol. Chem., 2002, 277, 7144-7147.

26 A. M. Hansen, A. L. Sewell, R. H. Pedersen, D. L. Long, N. Gadegaard and R. Marquez, Tetrahedron, 2013, 69, 8527-8533.

27 T. Holm, H. Johansson, P. Lundberg, M. Pooga, M. Lindgren and U. Langel, Nat. Protoc., 2006, 1, 1001-1005. 